DEMOGRAPHIC RESEARCH

VOLUME 39, ARTICLE 10, PAGES 315-336

PUBLISHED 10 AUGUST 2018

http://www.demographic-research.org/Volumes/Vol39/10/

DOI: 10.4054/DemRes.2018.39.10

Research Article

\title{
The influence of the number of siblings on expected family size in a cohort of young adults in Germany
}

Petra Buhr

Katharina Lutz

\section{Timo Peter}

This publication is part of the Special Collection on "The Power of the Family," organized by Guest Editors Hilde A.J. Bras and Rebecca Sear.

(C) 2018 Petra Buhr, Katharina Lutz \& Timo Peter.

This open-access work is published under the terms of the Creative Commons Attribution 3.0 Germany (CC BY 3.0 DE), which permits use, reproduction, and distribution in any medium, provided the original author(s) and source are given credit.

See https://creativecommons.org/licenses/by/3.0/de/legalcode. 


\section{Contents}

$\begin{array}{lll}1 & \text { Introduction } & 316\end{array}$

2 Previous findings, theoretical considerations and hypotheses 317

3 Data, sample, variables, and methods 321

3.1 Dependent variable 321

$\begin{array}{lll}3.2 & \text { Independent variables } & 322\end{array}$

3.3 Methods 324

$4 \quad$ Results $\quad 324$

4.1 Descriptive findings 324

$\begin{array}{lll}4.2 & \text { Multivariate findings } & 325\end{array}$

$5 \quad$ Summary and conclusion $\quad 329$

6 Acknowledgments 331

References 332 


\title{
The influence of the number of siblings on expected family size in a cohort of young adults in Germany
}

\author{
Petra Buhr ${ }^{1}$ \\ Katharina Lutz ${ }^{2}$ \\ Timo Peter ${ }^{2}$
}

\begin{abstract}
BACKGROUND

Previous research has shown that fertility is influenced by the family of origin. However, there is only little evidence about intergenerational transmission of fertility expectations in younger birth cohorts.
\end{abstract}

\section{OBJECTIVE}

We investigate if there is a positive relationship between the number of full siblings and expected family size in a young birth cohort in Germany and whether this association can be explained by transmission of socioeconomic status.

\section{METHODS}

We use the fifth wave of the German Family Panel (birth cohort 1991-1993) and estimate multinomial logistic regression models.

\section{RESULTS}

We find a positive effect of the number of full siblings on expected family size that remains stable when controlling for the socioeconomic status of the parents. The effect is smaller on an expected family size of two children compared to other parities which is compatible with the prevailing two-child norm in Germany. Contrary to our expectations there is no effect of the number of siblings on being uncertain about having children.

\section{CONCLUSION}

The family of origin influences fertility expectations in a cohort born in the 1990s in Germany, which cannot be explained by transmission of socioeconomic status. Although it is theoretically plausible, there is no final proof that the relationship is

\footnotetext{
${ }^{1}$ University of Bremen, SOCIUM Research Center on Inequality and Social Policy. Email: buhr@uni-bremen.de.

${ }^{2}$ University of Bremen, SOCIUM Research Center on Inequality and Social Policy.
} 
instead due to transmission of family values, as the number of siblings is only a proxy variable for the family values of the parents.

\section{CONTRIBUTION}

We verify the results of previous studies for a cohort born in the 1990s in Germany, account for parity differences, and include uncertainty in fertility expectations.

\section{Introduction}

There is a long tradition of research on the association between family of origin and fertility (Axinn, Clarkberg, and Thornton 1994; Barber 2000; Huinink 1987; Kolk 2014a, 2014b; Michael and Tuma 1985; Murphy 2013; Murphy and Wang 2001; Régnier-Loilier 2006; Rijken and Liefbroer 2009; Steenhof and Liefbroer 2008; Thornton 1980; Westoff and Potvin 1967). These studies found a positive relationship between the number of siblings and completed and, more seldom, expected family size. One explanation for the positive correlation between family of origin and fertility is transmission of family values and preferences from parents to children. However, other factors may also play a role, for example, the socioeconomic status of the parents, transmission of knowledge, model learning, or genetic factors (Kolk 2014b; Rijken and Liefbroer 2009; Steenhof and Liefbroer 2008; Thornton 1980). With few exceptions the previous studies apply to men and women born at the latest in the 1970s. Therefore, it is an open question whether the nexus between family of origin and fertility can also be observed in younger birth cohorts.

In our paper we contribute to the literature in three aspects: First, we analyse the relationship between the number of full siblings and fertility expectations in a cohort of young adults born in the early 1990s in Germany. Second, we account for parity differences in the dependent (realistically expected family size) and independent (number of full siblings) variables. Third, we include uncertainty about the realistically expected family size in our statistical models.

We use the fifth wave of the German Family Panel focussing on the birth cohort 1991-1993. Our dependent variable is realistically expected family size, and not completed family size, because we want to analyse the relationship between family of origin and fertility in a young birth cohort and only about $2 \%$ of the respondents of the birth cohort 1991-1993 were already parents at wave 5. In Germany the mean age of women when giving birth to their first child was 29.2 years in 2012. Even if it is widely acknowledged that fertility plans or intentions are not always realised (Philipov 2009), we think that it is acceptable to treat expected family size as a proxy variable for 
fertility behaviour. Given the availability and widespread use of good contraceptives, the number of unplanned births should be small.

In the following section we summarise previous findings and present our theoretical considerations and hypotheses. Afterward we describe the database, the variables and the methods used. In the fourth section we present the results of the statistical models. Finally, we summarise our results and draw some conclusions for further research.

\section{Previous findings, theoretical considerations and hypotheses}

Many studies have observed an association between family of origin and fertility desires and behaviour, especially a positive influence of the presence of siblings. ${ }^{3}$ Individuals with siblings have earlier births (Barber 2000, 2001; Huinink 1987; Kolk 2014b; Michael and Tuma 1985; Rijken and Liefbroer 2009; Rindfuss and John 1983; Steenhof and Liefbroer 2008) and end up with more children (Murphy and Knudsen 2002; Murphy and Wang 2001). There are comparatively few, and mostly older, studies that have explored the association between the number of siblings and fertility desires or expectations. Thornton (1980), who analysed data from the Panel Study of Income Dynamics (PSID) for couples from 1972-1974, found that the number of the husband's siblings had no significant effect on the ideal and expected family size. In contrast, Axinn, Clarkberg, and Thornton (1994) found, with US data, that the number of children a mother had borne had a positive influence on the family size preferences of their children at age 18. Heiland, Prskawetz, and Sanderson (2008) reported a positive influence of the number of siblings on the ideal family size of childless women under the age of 35 in Germany based on data from 1988 and 1994. Régnier-Loilier (2006) came to a similar conclusion with a French sample of men and women ages 15-45 conducted in 1998: The more siblings the respondent had, the higher the desired number of children. The additional value of this study is that it reveals differences according to parity. ${ }^{4}$ In particular, it was shown that the influence of the number of siblings was strongest on a desired family size of three and more children and relatively weak on a desired family size of two.

\footnotetext{
${ }^{3}$ In addition to the number of siblings, some authors use other indicators for experiences within the family of origin, e.g., the preferred family size of the parents (Thornton 1980), the family size preferences of parents for their children (Axinn, Clarkberg, and Thornton 1994; Barber 2000), the age of the parents at first birth (Kahn and Anderson 1992; Rijken and Liefbroer 2009; Steenhof and Liefbroer 2008) or the number of children the grandparents had (Kolk 2014a, 2014b).

${ }^{4}$ For parity differences in the relationship between number of siblings and risk of first birth see Kolk (2014a, 2014b).
} 
Most of the aforementioned studies on the intergenerational transmission of fertility refer to men and women born at the latest in the 1970s. Only two Dutch studies (Rijken and Liefbroer 2009; Steenhof and Liefbroer 2008) also cover birth cohorts born in the early 1980s. It is an open question if there is still an association between the family of origin and fertility in younger birth cohorts. There are theoretical arguments for finding as well as for not finding such a relationship in young cohorts (Murphy 2013; Murphy and Knudsen 2002; Steenhof and Liefbroer 2008). On the one hand it can be argued that the connection between family of origin and fertility should be lower in younger birth cohorts because individual achievements have gained more importance over the last decades. Due to modernisation and individualisation individual autonomy has increased and parents' influence on their offspring's life decisions has decreased. On the other hand it is also possible that parental influence has increased because "in the absence of generally shared norms, the individual has to rely on his or her personal network. If so, parental norms may be more relevant in modern individualistic societies than they used to be, and the effect may have been to increase intergenerational transmission" (Steenhof and Liefbroer 2008: 70). Another argument for an increase in intergenerational transmission is that, due to the availability of effective contraception, control over fertility behaviour has increased and "might enable women to match their own outcome more closely to that of their family of orientation" (Murphy 2013: 106). The empirical evidence rather points toward an increase of the association between family of origin and fertility over cohorts: Investigating several data sources collected in various industrialized countries Murphy and Wang (2001) found that the relationship between number of siblings and completed fertility increased over two successive cohorts born before 1950. Steenhof and Liefbroer (2008), who analysed the intergenerational transmission of age at first birth for Dutch birth cohorts born from 1935 to 1984, also found that the transmission effect was stronger in younger cohorts. The only German study, focussing on birth cohorts between 1919 and 1971, found that the association between number of siblings and number of births weakened over time (Buhr and Huinink 2015). However, the main aim of this study was to explain fertility development in East and West Germany and the number of siblings was only included as a control variable in the statistical models. Given the vast evidence pointing to a positive relationship between the number of siblings and fertility desires and outcomes and the plausible theoretical considerations on why the association should also be important in younger birth cohorts, our first hypothesis is:

Hypothesis 1: The number of siblings is positively correlated with the expected family size in a cohort of young adults born in the 1990s in Germany. 
We further assume that young adults orientate their fertility expectations not only according to the norms of their parents or peers, but also to general or societal norms (Bhrolcháin and Beaujouan 2015). In this respect especially the prevailing two-child norm in many countries (Testa 2007) might mitigate the association between the number of siblings and expected family size. This assumption is supported by empirical findings for Sweden and France: Kolk (2014a) found that the effect of the number of siblings on the transition to the second child was smaller than for the first child, and Régnier-Loilier (2006) reported that the proportion of respondents who wanted to have two children did not differ as much by the number of siblings than the proportion who wanted to have three and more children. Given the strong two-child norm present in Germany, it is plausible to assume that these results will also be true in the German context. We thus hypothesize that:

Hypothesis 1a: The association between the number of siblings and expecting to have two children is weaker than for expecting to have one child or three and more children.

One explanation for the relationship between the number of siblings and fertility is transmission of parental values and attitudes by socialisation (Thornton 1980; Huinink 1987; Régnier-Loilier 2006; Steenhof and Liefbroer 2008; Rijken and Liefbroer 2009). It is assumed that during children's socialisation the parents' values and attitudes are transferred to the next generation and influence the young generation's fertility expectations and outcomes. This explanation is supported by studies that observed higher fertility preferences and outcomes of the children if the mother has high fertility preferences (Axinn, Clarkberg, and Thornton 1994; Barber 2000). Assuming that having many brothers or sisters indicates a high family orientation of the parents and that family values are transferred to the children, individuals with (many) siblings should value having children higher than individuals with no (or fewer) siblings.

A different explanation for the association between number of siblings and fertility is that it is not family values that are transmitted, but the socioeconomic status of the family of origin (e.g., Thornton 1980; Kolk 2014b). If fertility is associated with socioeconomic status and socioeconomic status persists within generations, this may lead to the observed intergenerational correlations between the number of siblings and expected or completed family size. For example, low economic status is often associated with a young age at first birth and a higher number of children (Buhr and Huinink 2015; Kreyenfeld and Konietzka 2017). The low socioeconomic status may be transferred to the children and result in earlier and more births. However, the empirical evidence for the influence of parents' socioeconomic status on children's fertility is inconclusive. Rijken and Liefbroer (2009) found an effect of parental education and 
number of siblings on the age at first birth and completed family size in the Netherlands. Moreover, some of the effects of the parents' social status were mediated by the education of the children. Similar results were reported for German women by Huinink (1987). Also for Germany, Van Winkle et al. (2016) show that the transmission of fertility patterns is more likely for children who stay in the same social class as their parents compared to children who are upward mobile. On the other hand, Axinn, Clarkberg, and Thornton (1994) did not find a significant effect of parental education on the fertility preferences of children in the United States and Kolk (2014b) did not find a significant effect of parental socioeconomic status on completed fertility in Sweden. Moreover, applying stepwise regression models, several studies found that the effect of the number of children in the family of origin on fertility expectations and outcomes of the next generation was only slightly or not reduced at all once socioeconomic background variables were included in the statistical models (Thornton 1980; Murphy 2013; Kolk 2014b).

Thus, according to the literature, parental socioeconomic status might indeed affect the expected family size of the children. However, there is also evidence that the relationship between the number of siblings and fertility remains strong if the socioeconomic status of the parents is controlled. This is compatible with the assumption that the relationship between the number of siblings and fertility expectations cannot be explained by transmission of socioeconomic status alone, but that other factors, for example, transmission of family values, might also be important. Thus, our second hypothesis is:

Hypothesis 2: The effect of the number of siblings on expected family size is not or only partly reduced if the socioeconomic status of the parents is controlled.

Moreover, persons who grow up with siblings probably have more information about the potential costs and benefits of having their own children and the requirements of the parental role than respondents without siblings. We also know from the literature that a sizeable proportion of people are uncertain about the number of children they expect or desire (Morgan 1982; Bhrolcháin and Beaujouan 2015; Kuhnt and Buhr 2016). As lack of information is a potential source of uncertainty, we finally assume that:

Hypothesis 3: Persons without siblings are more likely to be uncertain about the number of children they expect than persons with siblings. 


\section{Data, sample, variables, and methods}

Analyses are based on data from the fifth wave of the German Family Panel, release 6.0 (Brüderl et al. 2015). The German Family Panel (pairfam) was launched in 2008 and is a multidisciplinary, longitudinal study for researching partnership and family dynamics in Germany with annual waves. ${ }^{5}$ The first wave was conducted in 2008/2009 with a nationwide random sample of over 12,000 participants from three birth cohorts (19711973, 1981-1983, 1991-1993) in East and West Germany. Due to panel mortality the number of participants has declined to about 6,300 at wave 5 .

We restrict our analysis to childless respondents of the youngest birth cohort who were not pregnant or whose partner was not pregnant. ${ }^{6}$ After having also excluded the few respondents who did not answer the question on their realistically expected family size (our dependent variable), the remaining sample size was 2,332. The respondents were 15 to 17 years old in 2008/2009 (first interview) and 19 to 21 years old in 2012/2013 (fifth interview). Due to missing values of the independent variables used in the multivariate analysis (listwise deletion) the number of cases is further reduced to 2,202 .

\subsection{Dependent variable}

Our dependent variable is the realistically expected family size. This variable is derived from the following question: "When you think realistically about having children, how many biological or adoptive children do you think you will have?" In the following, for reasons of simplicity, we will only speak of "expected family size." The answer categories are: $0,1,2,3,4$ and more children, not sure (5) and I haven't thought about that (6). For the analysis we pooled the categories 5 and 6 together as "uncertain" and the categories 3 and 4 and more children together as 3 and more children. It also has to be noted that we are not able to differentiate between uncertainty about the expected number of children and uncertainty about having any children at all. The distribution of the expected family size proves the prevalence of the two-child norm in Germany (see Table 1): About $60 \%$ of the respondents in our sample reported that they expected to have two children. Only about $4 \%$ did not expect to have children at all, while more than $10 \%$ were uncertain about their expected family size.

\footnotetext{
${ }^{5}$ A detailed description of the study can be found in Huinink et al. (2011).

${ }^{6}$ At wave 5 only 57 respondents of the youngest cohort already had children and ten reported a pregnancy.
} 


\subsection{Independent variables}

Our independent variable is the number of full siblings. This variable was recorded for the first time in wave 5. The number of full siblings was categorised into no siblings, one sibling, two siblings, and three and more siblings. Nearly half of the respondents have one full sibling (see Table 1), i.e., they grew up in a two-child family. About one fifth have no full sisters or brothers and $11 \%$ have three and more full siblings. The socioeconomic background of the parents is measured by the mother's and father's qualification levels. We use the CASMIN scale (König, Lüttinger, and Müller 1988) and distinguish three levels: low (basic vocational training and less), medium (intermediate vocational training and general qualifications) and high (all levels above). If the information was available for both parents, we calculated the mean of both qualification levels. Otherwise we used the qualification level of the parent for whom the information was available. ${ }^{7}$ Less than one fifth of the respondents have parents with a low qualification level.

Moreover, we use several control variables. As some studies have found that the presence of siblings other than full siblings is also important for fertility behaviour (e.g., Murphy and Knudsen 2002), we also included the number of other siblings in the statistical models. To be more precise, we only allow for those other siblings with whom the respondents have lived together at least half of their childhood. The reason for the restriction is that it can be assumed that only other siblings with whom the respondents have actually lived together for some time will influence their fertility expectations. Because of the relatively low number of cases we only use three categories for other siblings: no other siblings, one other sibling, two and more other siblings. Finally, we included several other control variables in our statistical models which have proved to be important for fertility intentions and desires in Germany (see e.g., Buhr et al. 2011; Philipov and Berghammer 2007; Ruckdeschel 2004). The distribution and/or means of these variables are shown in Table 1:

- $\quad$ Sex (male vs. female)

- Highest school degree: lower = no degree, secondary general school leaving certificate (Hauptschule); intermediate $=$ intermediate school leaving certificate (Realschule, Mittlere Reife); upper = entrance qualification for universities of applied science (Fachhochschulreife), general or subject-specific university entrance qualification (Abitur). The few respondents who still were enrolled were assigned according to the current school type.

- Education status (not in education vs. in education)

\footnotetext{
${ }^{7}$ Alternatively, we used the highest qualification of the father or the mother to generate the qualification variable. The results remained nearly unchanged.
} 
- $\quad$ Place of residence (West vs. East Germany)

- Partnership status (single, partner no cohabitation, partner with cohabitation)

- Migration background (migration background vs. German native without migration background)

- Religiousness (measured by the variable "importance of God," 11-point scale from $0=$ not at all important to $10=$ very important).

Table 1: Distribution of the dependent and independent variables in the sample

\begin{tabular}{|c|c|c|}
\hline Variable & Number of cases & Percent \\
\hline \multicolumn{3}{|l|}{ Expected family size $($ Mean $=1.96)$} \\
\hline 0 & 85 & 3.9 \\
\hline 1 & 246 & 11.2 \\
\hline 2 & 1,315 & 59.7 \\
\hline 3 and more & 330 & 15.0 \\
\hline Uncertain & 226 & 10.3 \\
\hline \multicolumn{3}{|l|}{ Number of full siblings $($ Mean $=1.32$ ) } \\
\hline 0 & 430 & 19.5 \\
\hline 1 & 1,057 & 48.0 \\
\hline 2 & 468 & 21.3 \\
\hline 3 and more & 247 & 11.2 \\
\hline \multicolumn{3}{|l|}{$\begin{array}{l}\text { Number of other siblings with whom respondent has lived } \\
\text { together at least half of childhood (Mean }=0.13 \text { ) }\end{array}$} \\
\hline 0 & 2,000 & 90.8 \\
\hline 1 & 138 & 6.3 \\
\hline 2 and more & 64 & 2.9 \\
\hline \multicolumn{3}{|l|}{ Qualification level of parents } \\
\hline Low & 424 & 19.3 \\
\hline Medium & 1,261 & 57.3 \\
\hline High & 517 & 23.5 \\
\hline \multicolumn{3}{|l|}{ Sex } \\
\hline Male & 1,140 & 51.8 \\
\hline Female & 1,062 & 48.2 \\
\hline \multicolumn{3}{|l|}{ Place of residence } \\
\hline West Germany & 1,788 & 81.2 \\
\hline East Germany & 414 & 18.8 \\
\hline \multicolumn{3}{|l|}{ Highest school degree } \\
\hline Lower & 356 & 16.2 \\
\hline Intermediate & 603 & 27.4 \\
\hline Upper & 1,243 & 56.5 \\
\hline \multicolumn{3}{|l|}{ Partnership status } \\
\hline Single & 1,153 & 52.4 \\
\hline With partner & 860 & 39.1 \\
\hline Cohabitation & 189 & 8.6 \\
\hline \multicolumn{3}{|l|}{ Migration background } \\
\hline Migration background & 451 & 20.5 \\
\hline German native, no migration background & 1,751 & 79.5 \\
\hline \multicolumn{3}{|l|}{ Education status } \\
\hline Not in education & 750 & 34.1 \\
\hline In education (e.g., university, vocational training) & 1,452 & 65.9 \\
\hline Importance of God (Mean = 3.38) & 2,202 & \\
\hline
\end{tabular}

Note: Database: Pairfam, wave 5, release 6.0; sample: birth cohort 1991-1993, no children, not pregnant. 


\subsection{Methods}

We first present some descriptive results on the relationship between full siblings and expected family size. Afterward, we estimate multinomial logistic regression models with expected family size as the dependent variable (answer categories: no children, one child, two children, three and more children, and uncertain). We proceed in three steps: In Model 1 we analyse the influence of the number of full siblings on expected family size, controlling for other siblings, gender, region, partnership status, migration status, education status, and importance of God. In Model 2 we additionally control for the qualification level of the parents, to find out if the effect of the number of siblings on expected family size can (partly) be explained by parents' socioeconomic status. As the effect of the socioeconomic status of the parents may be mediated by the educational achievement of the children, in Model 3 we further include the highest school degree of the respondents. If, after controlling for these two socioeconomic variables, the effect of the number of siblings on expected family size was to decrease, this would mean that the effect of the number of siblings on expected family size partly reflects the socioeconomic status of the respondent's parental home.

In a multinomial logit model, one group or category of the dependent variable has to be defined as a reference or base category and the effects in the other groups have to be related to this base category. As the results of multinomial logistic regression models strongly depend on the choice of the reference category for the dependent variable and as it is argued that it is problematic to compare the logit coefficients of logistic regressions between different models (see e.g., Mood 2010), we calculated average marginal effects (AMEs). The average marginal effect indicates the change in probability if an independent variable changes by one unit. If the independent variable is a categorical one, the effect indicates the change from the reference category of this variable. The AMEs can be calculated for all categories of the dependent variable including the base category.

\section{Results}

\subsection{Descriptive findings}

As expected, there is a positive relationship between the number of full siblings and expected family size (Table 2): The higher the number of full siblings, the more children are expected. While nearly $30 \%$ of respondents with three and more full siblings expect to have three and more children, this is true for only $8 \%$ of respondents without any full siblings and for about $10 \%$ of those with one full sibling. This means 
that the difference between those with three and more siblings and those with no siblings or one sibling is about 20 percentage points. Among the respondents expecting to have two children, the difference between those with three and more full siblings and no full siblings is only 8 percentage points and between those with three and more siblings and one sibling only 16 percentage points. This supports the assumption that the two-child norm may diminish the relationship between number of siblings and fertility expectations. In contrast to our expectation, the proportion of respondents who are uncertain about the expected number of children does not differ according to the number of full siblings.

Table 2: Realistically expected family size by number of full siblings (percent)

\begin{tabular}{|c|c|c|c|c|c|c|c|}
\hline & Mean & No children & 1 child & 2 children & 3 and more children & Uncertain & $\mathrm{N}=100 \%$ \\
\hline \multicolumn{8}{|l|}{ Full siblings } \\
\hline 0 & 1.75 & 5.8 & 19.5 & 57.7 & 8.4 & 8.6 & 430 \\
\hline 1 & 1.92 & 3.7 & 9.9 & 65.7 & 10.3 & 10.4 & 1,057 \\
\hline 2 & 2.10 & 3.6 & 7.7 & 53.4 & 23.9 & 11.3 & 468 \\
\hline 3 and more & 2.20 & 1.6 & 8.5 & 49.8 & 29.6 & 10.5 & 247 \\
\hline $\mathrm{N}$ & 1,976 & 85 & 246 & 1,315 & 330 & 226 & 2,202 \\
\hline
\end{tabular}

Note: Database: Pairfam, wave 5, release 6.0; sample: birth cohort 1991-1993, no children, not pregnant.

\subsection{Multivariate findings}

The results of the multinomial logistic models are presented in three steps. In Model 1 (Table 3) we present the AMEs without controlling for the parents' socioeconomic status and respondents' highest school degree; in Model 2 (Table 4) the socioeconomic status of the parents is controlled for and in Model 3 (Table 5) the highest school degree of the respondent is included.

In accordance with our first hypothesis, there is a positive relationship between the number of full siblings and expected family size (Table 3 ). However, there are also clear differences according to parity at the side of the dependent and the independent variable: Respondents with one, two, and three and more full siblings have a lower probability of expecting to remain childless compared to those without full siblings. However, the effects are small and, with the exception of three and more full siblings, not significant. This means that there is no clear cut difference between respondents with and without full siblings in relation to an expected family size of no children. In contrast, there is a strong and significant effect of the number of full siblings on expecting one child. Compared to those without full siblings, the probability of expecting one child is 8 percentage points lower for respondents with one full sibling, 10 percentage points lower for those with two full siblings and 7 percentage points 
lower for respondents with three and more full siblings. While respondents with one full sibling have a higher probability of expecting two children, the effects are negative for those with two and three and more children. However, the effects on expecting two children are not significant for respondents with two siblings and significant at the 5\% level only for those with one sibling and three and more full siblings. This indicates that there is no strong difference between respondents without and with full siblings in relation to an expected family size of two, which is at least partly in accordance with our hypothesis 1a about the relevance of the two-child-norm. Finally, while there is no significant effect for respondents with one full sibling, those with two and three and more siblings have a much higher probability of expecting three and more children. Compared to respondents without full siblings, the probability of expecting three and more children is 15 percentage points higher if the respondent has two full siblings and even 17 percentage points higher if the respondent has three and more full siblings. Contrary to our expectations, there is no effect of the number of full siblings on the probability of being uncertain about expected family size. A higher number of siblings does not reduce the amount of uncertainty regarding the expected number of children.

Table 3: Effect of number of siblings on realistically expected family size: Model 1 (AMEs)

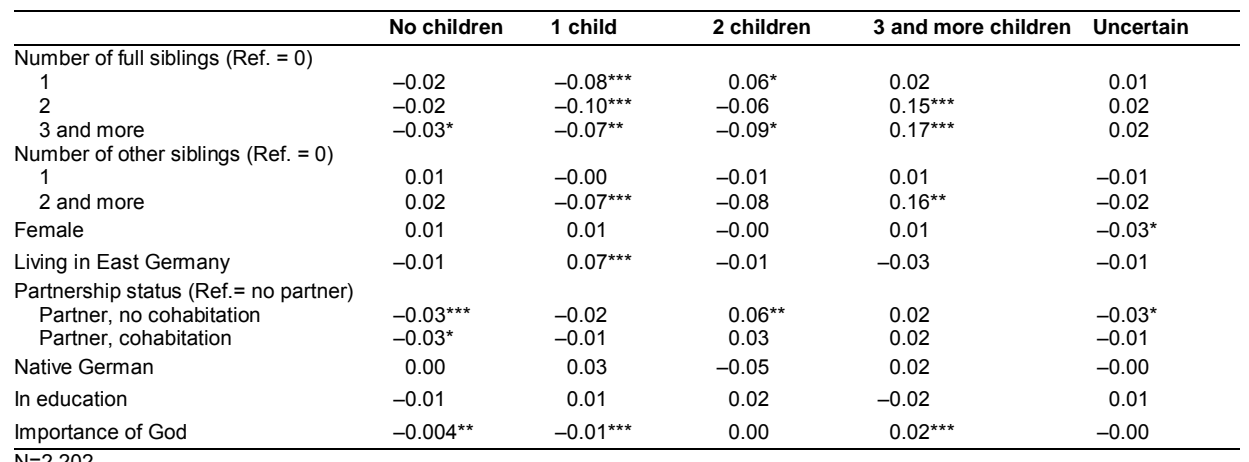

$\mathrm{N}=2,202$

LR chi2 $(48)=303.82$

Prob $>$ chi2 $=0.00$

Pseudo R2 $=0.058$

Note: ${ }^{* * *} p \leq 0.001,{ }^{* *} p \leq 0.01,{ }^{*} p \leq 0.05$. Database: Pairfam, wave 5, release 6.0; sample: birth cohort 1991-1993, no children, not pregnant.

As to other siblings, there are only two significant effects: Respondents with two and more other siblings have a higher probability of expecting three and more children and a lower one of expecting one child in comparison to those without other siblings. 
Note that we only allowed for other siblings with whom the respondent has spent at least half of the childhood.

Regarding the other control variables, women have a lower probability than men to be uncertain about the number of children they expect to have. Respondents who live in East Germany have a higher probability to expect one child than those in West Germany, which corresponds with the higher percentage of one-child-families in East Germany. Respondents who do not cohabitate with their partner have a lower probability to expect no children and to be uncertain than those without a partner and a higher probability to expect two children. Those who live together with their partner also have a lower probability of expecting no children. The effects for one and more children are small and not significant. However, we have to keep in mind that less than $10 \%$ of the young respondents in our sample already cohabitate. Finally, higher scores on the importance of God decreased the probability of expecting no children or one child and increased the probability of expecting three and more children.

Table 4: $\quad$ Effect of number of siblings on realistically expected family size: Model 2 (AMEs)

\begin{tabular}{|c|c|c|c|c|c|}
\hline & No children & 1 child & 2 children & 3 and more children & Uncertain \\
\hline \multicolumn{6}{|c|}{ Number of full siblings (Ref. $=0$ ) } \\
\hline 1 & -0.02 & $-0.08^{\star \star *}$ & $0.06^{*}$ & 0.02 & 0.01 \\
\hline 2 & -0.02 & $-0.10^{* \star *}$ & -0.06 & $0.15^{\star \star *}$ & 0.02 \\
\hline 3 and more & $-0.04^{*}$ & $-0.08^{* *}$ & $-0.08^{*}$ & $0.18^{* * *}$ & 0.02 \\
\hline \multicolumn{6}{|c|}{ Number of other siblings (Ref. $=0$ ) } \\
\hline 1 & 0.01 & -0.01 & -0.00 & 0.01 & -0.01 \\
\hline 2 and more & 0.01 & $-0.08^{* * *}$ & -0.09 & $0.17^{\star *}$ & -0.02 \\
\hline Female & 0.01 & 0.01 & -0.00 & 0.01 & $-0.03^{*}$ \\
\hline Living in East Germany & -0.01 & $0.07^{\star \star \star}$ & -0.02 & -0.03 & -0.01 \\
\hline \multicolumn{6}{|c|}{ Partnership status (Ref.= no partner) } \\
\hline Partner, no cohabitation & $-0.03^{\star \star *}$ & -0.03 & $0.06^{\star \star}$ & 0.03 & $-0.03^{*}$ \\
\hline Partner, cohabitation & $-0.03^{*}$ & -0.01 & 0.03 & 0.03 & -0.01 \\
\hline Native German & 0.00 & 0.03 & -0.05 & 0.02 & -0.00 \\
\hline In education & -0.01 & 0.01 & 0.02 & -0.02 & 0.01 \\
\hline Importance of God & $-0.004^{* *}$ & $-0.01^{* \star *}$ & 0.00 & $0.02^{\star * *}$ & -0.00 \\
\hline \multicolumn{6}{|c|}{ Parents' level of qualification (Ref. $=$ low) } \\
\hline Medium & -0.01 & -0.04 & 0.04 & 0.00 & 0.00 \\
\hline High & -0.02 & $-0.06^{\star *}$ & -0.02 & $0.08^{* * *}$ & 0.02 \\
\hline \multicolumn{6}{|l|}{$\mathrm{N}=2,202$} \\
\hline \multicolumn{6}{|l|}{ LR chi2 $(56)=329.71$} \\
\hline \multicolumn{6}{|l|}{ Prob $>$ chi2 $=0.00$} \\
\hline Pseudo R2 $=0.063$ & & & & & \\
\hline
\end{tabular}

Note: ${ }^{* *} p \leq 0.001,{ }^{* *} p \leq 0.01,{ }^{*} p \leq 0.05$. Database: Pairfam, wave 5, release 6.0; sample: birth cohort 1991-1993, no children, not pregnant.

In Model 2 (Table 4) we further control for the parents' socioeconomic status. Respondents whose parents have a high level of qualification have a lower probability to expect one child and a higher probability to expect three and more children than 
those whose parents have a low level. The effect of the control variables is not changed by including the parents' level of qualification. However, the most important result of Model 2 is that the effect of the number of siblings on the expected family size remains nearly unchanged when we account for the socioeconomic status of the respondent's parents. This means that the effect of the number of siblings on expected family size cannot be explained by the socioeconomic status of the parents which is in compliance with our second hypothesis. However, it is possible that the socioeconomic status of the parents is mediated by the educational level of the children. Therefore, in the final Model 3 we also included the highest school degree of the respondent.

Table 5: Effect of number of siblings on realistically expected family size: Model 3 (AMEs)

\begin{tabular}{|c|c|c|c|c|c|}
\hline & No children & 1 child & 2 children & 3 and more children & Uncertain \\
\hline \multicolumn{6}{|c|}{ Number of full Siblings (Ref. $=0$ ) } \\
\hline 1 & -0.02 & $-0.08^{\star * *}$ & $0.06^{\star}$ & 0.02 & 0.01 \\
\hline 2 & -0.02 & $-0.10^{\star \star \star}$ & -0.05 & $0.15^{\star * *}$ & 0.02 \\
\hline 3 and more & $-0.04^{\star *}$ & $-0.08^{\star *}$ & $-0.08^{*}$ & $0.18^{* * *}$ & 0.02 \\
\hline \multicolumn{6}{|c|}{ Number of other siblings (Ref. $=0$ ) } \\
\hline 1 & 0.01 & -0.01 & -0.00 & 0.01 & -0.01 \\
\hline 2 and more & 0.01 & $-0.08^{\star \star \star}$ & -0.09 & $0.17^{\star \star}$ & -0.02 \\
\hline Female & 0.01 & 0.02 & -0.00 & 0.00 & $-0.03^{*}$ \\
\hline Living in East Germany & -0.01 & $0.07^{* * *}$ & -0.02 & -0.03 & -0.01 \\
\hline \multicolumn{6}{|c|}{ Partnership Status (Ref.= no partner) } \\
\hline Partner, no cohabitation & $-0.03^{\star * *}$ & -0.03 & $0.06^{\star *}$ & 0.02 & $-0.03^{*}$ \\
\hline Partner, cohabitation & $-0.03^{*}$ & -0.01 & 0.03 & 0.03 & -0.01 \\
\hline Native German & 0.00 & 0.03 & -0.05 & 0.01 & -0.00 \\
\hline In education & -0.01 & 0.01 & 0.02 & -0.03 & 0.01 \\
\hline Importance of God & $-0.004^{\star *}$ & $-0.01^{\star \star *}$ & 0.00 & $0.02^{* * *}$ & -0.00 \\
\hline \multicolumn{6}{|c|}{ Parents' level of qualification (Ref.= low) } \\
\hline Medium & -0.00 & -0.03 & 0.03 & -0.01 & 0.00 \\
\hline High & 0.00 & -0.05 & -0.03 & $0.06^{\star *}$ & 0.01 \\
\hline \multicolumn{6}{|c|}{ Highest school degree (Ref. == low) } \\
\hline Medium & -0.03 & -0.02 & $0.08^{\star \star}$ & -0.02 & -0.01 \\
\hline High & $-0.05^{\star \star}$ & -0.03 & 0.05 & 0.03 & 0.00 \\
\hline \multicolumn{6}{|l|}{$\mathrm{N}=2,202$} \\
\hline \multicolumn{6}{|l|}{ LR chi2 $(64)=353.75$} \\
\hline \multicolumn{6}{|l|}{ Prob $>$ chi $2=0.00$} \\
\hline Pseudo R2 $=0.067$ & & & & & \\
\hline
\end{tabular}

Note: ${ }^{* * *} p \leq 0.001,{ }^{* *} p \leq 0.01,{ }^{*} p \leq 0.05$. Database: Pairfam, wave 5, release 6.0; sample: birth cohort 1991-1993, no children, not pregnant.

According to Model 3 (Table 5), the probability of expecting to remain childless is lower for respondents with a higher school degree in comparison to those with a lower degree. And respondents with a medium level have a higher probability of expecting two children than those with a lower level. The effect of the socioeconomic status of the parents on the expected family size of the children is slightly reduced in comparison to Model 2 in which the educational level of the respondent was not included. This 
indicates that both variables are indeed related to one another. However, the effect of the number of full siblings on expected family size remains unchanged. Again, this confirms the conclusion that the relationship between the number of full siblings and the expected number of children cannot be explained by the socioeconomic status of the family of origin.

\section{Summary and conclusion}

Although the relationship between family of origin and fertility has been studied intensively in the past, little is known if this association is also true for fertility expectations in younger cohorts. The aim of our paper thus was to investigate the influence of the number of siblings on expected family size in the cohort of young adults born between 1991 and 1993 in Germany. We accounted for parity differences in the main independent (number of full siblings) and the dependent variable (realistically expected number of children), including uncertainty of fertility expectations. We used the fifth wave of the German Family Panel (pairfam) and estimated multinomial logistic regression models.

In accordance with our first hypothesis, we found a positive association between the number of full siblings and expected family size. Respondents without full siblings had the highest probability of expecting no children or one child, respondents with one full sibling had the highest probability of expecting two children, and respondents with two and more siblings had the highest probability of expecting three or more children. The strongest relationship was found between having three and more full siblings and expecting three and more children. Thus, young adults in Germany tend to expect a family size similar to their family of origin, especially if they come from a large family. The relationship between the number of full siblings and expected family size proved to be weaker for expecting to have two children than for expecting to have one child or three and more children. This is in accordance with our subhypothesis 1a and an indication that the relationship between the number of siblings and expected family size is lowered by the prevailing two-child-norm in Germany. There is also only a weak association between the number of siblings and expecting no children. This result is plausible if we take into account that childlessness cannot be "learnt" in the family of origin. Expecting to have no children may be based on factors which are independent of the number of siblings, e.g., critical life-events, competing life goals which are incompatible with having children or special risk factors (e.g., genetic diseases which might be passed on to the children).

There is no significant relationship between the number of full siblings and uncertainty about the expected family size. This is contrary to our expectation that 
respondents with siblings are less likely to be uncertain about their fertility expectations, as living with siblings provides information about the possible advantages and disadvantages of having children and the requirements of the parental role (H3). One explanation for this unexpected result is that the uncertainty category does not differentiate between uncertainty about having any children at all and uncertainty about the expected number of children. It is possible that having siblings decreases the uncertainty to have children at all, but increases the uncertainty about the number of expected children. Moreover, the concept of realistically expected family size is more concrete than the ideal or desired family size because it takes into account possible obstacles for family formation. Therefore, even if respondents with many siblings ideally wish to have many children, they may be uncertain if they can realistically achieve this ideal, as for example, having many siblings may coincide with difficult economic conditions in the family of origin.

As to the influence of the socioeconomic status of the family of origin, we found that respondents whose parents have a high level of qualification were less likely expecting to have one child and more likely expecting to have three and more children. However, the inclusion of the parents' socioeconomic status into the model did not reduce the influence of the number of siblings. This is in accordance with our second hypothesis (H2) and means that the association between family of origin and expected family size cannot be explained by transmission of socioeconomic status alone.

To sum up, according to our results, the positive relationship between family of origin and fertility, which was reported for older birth cohorts, was also found in a cohort of young adults born in the early 1990s in Germany. However, there are still at least two open questions to be addressed to in future research. First, there is clear evidence that the relationship between family of origin and fertility cannot be explained by transmission of parental socioeconomic status, because the influence of the family of origin remains unchanged if the socioeconomic status is controlled in the statistical models. However, we still do not know for sure how the relationship can be explained instead. Although it is theoretically highly plausible that the observed relationship between number of siblings and expected family size is due to transmission of family values, we cannot finally prove this assumption with our data. The reason is that we have no direct measure of the family values and preferences of the parents of the respondents and treated the number of siblings as a proxy variable. To analyse the transmission of values we have to wait until the respondents of the cohort 1991-1993 have children themselves. Second, due to our focus on a young birth cohort which has not yet started its family career, we used expected family size as a proxy for prospective fertility behaviour. As there is always a gap between fertility expectations or intentions and behaviour, we cannot be sure if the same results can be obtained for completed family size. Therefore, the analysis should be redone once the respondents of the birth 
cohort 1991-1993 have reached the end of their fertile period. Thus, even though we could shed light on some new aspects according to the relationship between family of origin and fertility, there is still further research to be done to explain this relationship in full detail.

\section{Acknowledgments}

This paper uses data from the German Family Panel pairfam, coordinated by Josef Brüderl, Sonja Drobnič, Karsten Hank, Bernhard Nauck, Franz Neyer, and Sabine Walper. Pairfam is funded as a long-term project by the German Research Foundation (DFG). 


\section{References}

Axinn, W.G., Clarkberg, M.E., and Thornton, A. (1994). Family influences on family size preferences. Demography 31(1): 65-79. doi:10.2307/2061908.

Barber, J.S. (2000). Intergenerational influences on the entry into parenthood: Mothers' preferences for family and nonfamily behavior. Social Forces 79(1): 319-348. doi:10.1093/sf/79.1.319.

Barber, J.S. (2001). The intergenerational transmission of age at first birth among married and unmarried men and women. Social Science Research 30(2): 219247. doi:10.1006/ssre.2000.0697.

Bhrolcháin, M.N. and Beaujouan, E. (2015). How real are reproductive goals? Uncertainty and the construction of fertility preferences. Southampton: ESRC Centre for Population Change (Working Paper 73).

Brüderl, J., Hank, K., Huinink, J., Nauck, B., Neyer, F.J., Walper, S., Alt, P., Buhr, P., Castiglioni, L., Finn, C., Hajek, K., Herzig, M., Huyer-May, B., Lenke, R., Müller, B., Peter, T., Salzburger, V., Schmiedeberg, C., Schubach, E., Schütze, P., Schumann, N., Thönnissen, C., and Wilhelm, B. (2015). The German family panel (pairfam): Data file version 6.0.0 [dataset]. Cologne: GESIS LeibnizInstitut für Sozialwissenschaften. doi:10.4232/pairfam.5678.6.0.0.

Buhr, P. and Huinink, J. (2015). The German low fertility: How we got there and what we can expect for the future. European Sociological Review 31(2): 197-210. doi:10.1093/esr/jcv013.

Buhr, P., Huinink, J., Boehnke, M., and Maul, K. (2011). Kinder oder keine? Institutionelle Rahmenbedingungen und biographische Voraussetzungen für die Familiengründung und -erweiterung in Ost- und Westdeutschland. In: Brüderl, J., Castiglioni, L., and Schumann, N. (eds.). Partnerschaft, Fertilität und intergenerationale Beziehungen: Ergebnisse der ersten Welle des Beziehungsund Familienpanels. Würzburg: Ergon Verlag: 175-201.

Heiland, F., Prskawetz, A., and Sanderson, W.C. (2008). Are individuals' desired family sizes stable? Evidence from West German panel data. European Journal of Population 24(2): 129-156. doi:10.1007/s10680-008-9162-x.

Huinink, J. (1987). Soziale Herkunft, Bildung und das Alter bei der Geburt des ersten Kindes. Zeitschrift fur Soziologie 16(5): 367-384. doi:10.1515/zfsoz-1987-0504. 
Huinink, J., Brüderl, J., Nauck, B., Walper, S., Castiglioni, L., and Feldhaus, M. (2011). Panel Analysis of Intimate Relationships and Family Dynamics (pairfam): Conceptual framework and design. Zeitschrift für Familienforschung 23(1): 77101.

Kahn, J.R. and Anderson, K.E. (1992). Intergenerational patterns of teenage fertility. Demography 29(1): 39-57. doi:10.2307/2061362.

König, W., Lüttinger, P., and Müller, W. (1988). A comparative analysis of the development and structure of educational systems: Methodological foundations and the construction of a comparative educational scale. Mannheim: Universität Mannheim, Institut für Sozialwissenschaften (CASMIN Working Paper 12).

Kolk, M. (2014a). Multigenerational transmission of family size in contemporary Sweden. Population Studies 68(1): 111-129. doi:10.1080/00324728.2013. 819112.

Kolk, M. (2014b). Understanding transmission of fertility across multiple generations: Socialization or socioeconomics? Research in Social Stratification and Mobility 35: 89-103. doi:10.1016/j.rssm.2013.09.006.

Kreyenfeld, M. and Konietzka, D. (2017). Childlessness in East and West Germany: Long-term trends and social disparities. In: Kreyenfeld, M. and Konietzka, D. (eds.). Childlessness in Europe: Contexts, causes, and consequences. Cham: Springer: 97-114. doi:10.1007/978-3-319-44667-7_5.

Kuhnt, A.-K. and Buhr, P. (2016). Biographical risks and their impact on uncertainty in fertility expectations: A gender-specific study based on the German Family Panel. Duisburg: Institut für Soziologie, Universität Duisburg-Essen (Duisburger Beiträge zur soziologischen Forschung 2016-03).

Michael, R.T. and Tuma, N.B. (1985). Entry into marriage and parenthood by young men and women: The influence of family background. Demography 22(4): 514544. doi:10.2307/2061586.

Mood, C. (2010). Logistic regression: Why we cannot do what we think we can do, and what we can do about it. European Sociological Review 26(1): 67-82. doi:10. 1093/esr/jcp006.

Morgan, S.P. (1982). Parity-specific fertility intentions and uncertainty: The United States, 1970 to 1976. Demography 19(3): 315-334. doi:10.2307/2060974. 
Murphy, M. (2013). Cross-national patterns of intergenerational continuities in childbearing in developed countries. Biodemography and Social Biology 59(2): 101-126. doi:10.1080/19485565.2013.833779.

Murphy, M. and Knudsen, L.B. (2002). The intergenerational transmission of fertility in contemporary Denmark: The effects of number of siblings (full and half), birth order, and whether male or female. Population Studies 56(3): 235-248. doi: $10.1080 / 00324720215937$.

Murphy, M. and Wang, D. (2001). Family-level continuities in childbearing in lowfertility societies. European Journal of Population 17(1): 75-96. doi:10.1023/ A:1010744314362.

Philipov, D. (2009). Fertility intentions and outcomes: The role of policies to close the gap. European Journal of Population 25(4): 355-361. doi:10.1007/s10680-0099202-1.

Philipov, D. and Berghammer, C. (2007). Religion and fertility ideals, intentions and behaviour: A comparative study of European countries. Vienna Yearbook of Population Research 2007(5): 271-305. doi:10.1553/populationyearbook2007 s271.

Régnier-Loilier, A. (2006). Influence of own sibship size on the number of children desired at various times of life: The case of France. Population 61(3): 165-194. doi:10.3917/pope.603.0165.

Rijken, A.J. and Liefbroer, A.C. (2009). Influences of the family of origin on the timing and quantum of fertility in the Netherlands. Population Studies 63(1): 71-85. doi:10.1080/00324720802621575.

Rindfuss, R.R. and John, C.S. (1983). Social determinants of age at first birth. Journal of Marriage and Family 45(3): 553-565. doi:10.2307/351660.

Ruckdeschel, K. (2004). Determinanten des Kinderwunsches in Deutschland. Zeitschrift für Bevölkerungswissenschaft 29(3-4): 363-386.

Steenhof, L. and Liefbroer, A.C. (2008). Intergenerational transmission of age at first birth in the Netherlands for birth cohorts born between 1935 and 1984: Evidence from municipal registers. Population Studies 62(1): 69-84. doi:10.1080/ 00324720701788616 .

Testa, M.R. (2007). Childbearing preferences and family issues in Europe: Evidence from the Eurobarometer 2006 survey. Vienna Yearbook of Population Research 2007(1): 357-379. doi:10.1553/populationyearbook2007s357. 
Thornton, A. (1980). The influence of first generation fertility and economic status on second generation fertility. Population and Environment 3(1): 51-72. doi:10. 1007/BF01253070.

Van Winkle, Z., Fasang, A., and Raab, M. (2016). Intergenerational patterns of family formation in East and West Germany. In: Ritschard, G. and Studer, M. (eds). Proceedings of the International Conference on Sequence Analysis and Related Methods. Lausanne: Swiss National Centre of Competence in Research: 509534.

Westoff, C.F. and Potvin, R.H. (1967). College women and fertility values. Princeton: Princeton University Press. doi:10.1515/9781400876051. 
Buhr, Lutz \& Peter: The influence of the number of siblings on expected family size 